\title{
Pre- and Early-Pandemic Graduating Students' Perceptions at a United States Business School
}

\author{
Gary Blau ${ }^{1}$ \\ ${ }^{1}$ Fox School of Business \& Management, Temple University, Philadelphia, PA, United States \\ Correspondence: Gary Blau, Human Resource Management Dept. - Fox School of Business \& Management, \\ Alter Hal \#349 (006-00) - 1801 Liacouras Walk, Temple University, Philadelphia, PA 19122, USA. Tel: \\ 1-215-204-6906.
}

Received: July 19, 2021 Accepted: August 23, $2021 \quad$ Online Published: August 30, 2021

doi:10.5539/jedp.v11n2p47

URL: http://doi.org/10.5539/jedp.v11n2p47

\begin{abstract}
Two separate samples of graduating business students completed online surveys in the Spring 2019 (pre-pandemic, $\mathrm{n}=724$ ) and Spring 2020 (early pandemic, $\mathrm{n}=376$ ). This research study explored changes in student grading assessment learning perceptions (GALP) between Spring of 2019 to Spring of 2020, as well as perceptions of video vault use, number of internships/co-ops completed, satisfaction with major, and satisfaction with business degree. With the abrupt change from face-to-face to all online classes in the middle of the Spring 2020 semester due to the pandemic, individual engagement GALP (e.g., attendance, participation) declined but video vault use increased. Reassuringly, other GALP scales as well as both satisfaction measures remained stable. Testing for changes in correlations from 2019 to 2020, using the four GALP scales, video vault use, and internships/co-ops completed as the independent variables and satisfaction with major and satisfaction with business degree as the dependent variables, there were several significant correlational changes. The correlation of video vault use to satisfaction with major increased from 2019 to 2020. Increased Individual Creative GALP - satisfaction with business degree, and Individual Engagement GALP - satisfaction with business degree correlations were also found. The positive Spring 2020 video vault use findings, and maintained GALP scale perceptions were at least partially due to the immediate online Zoom faculty training facilitated by the Business School Online and Digital Learning Department. However, there was a negative correlation from 2019 to 2020 in the internship/co-op completed - satisfaction with business degree. Study limitations and future research issues with the continuing pandemic are discussed.
\end{abstract}

Keywords: pandemic, grading assessment learning perceptions, business student satisfaction

\section{Introduction}

\subsection{Introduce the Problem}

In spite of recent progress with vaccinations, virus variants of the the COVID-19 pandemic continue to bring health, economic and social upheaval, and much cause for concern, to millions of people around the world (Plater, 2021). Friga (2021) estimated that the pandemic has cost United States (US) colleges $\$ 183$ billion in lost revenue for 2020. These revenue losses have culminated in some college closures, not only in the US (Sainato, 2021) but in other countries. For example, COVID-19 forced the closure of seveal colleges in Nigeria (Chinwana, Chinawa, Ossai, Aronu, \& Onukwuli, 2021). Much uncertainty remains for many universities and colleges around the world about how "normal" college campus life will be for returning students, faculty and staff in the Fall 2021 (McCormack, Lemoine, Waller, \& Richardson, 2021). Recent research on college students in the early pandemic stage found more experienced panic with higher COVID-19 fears and elevated depressive mood (Hasratian, Nordberg, Meuret, \& Riz, 2021; Konstantopoulou \& Raikou, 2020), as well as the need for modifable prevention intervention strategies to appreciate student perceived barriers and self-efficacy (Tam, Li, Li, Wang, \& Lin, 2021). McCormack et al. (2021) recommended that global higher education institutions focus on long-range planning over crisis management, and increase awareness/monitoring of learning design quality to help lessen this uncertainty. Prior work has focused on various college-level teaching issues caused by the pandemic, at both a country level (e.g., Balakrishnan, 2020) and specific University level (Neuwirth, Jovic, \& Mukherji, 2020). These teaching issues include: stronger benchmarking to help with student online learning and instructional design, 
greater student digital skills training and online resource availability, increased online course training for teachers/professors, and more realistic, work-applied online learning simulations for students (Rapanta, Botturi, Goodyear, Guardia, \& Koole, 2020).

\subsection{Revelant Scholarship}

Less empirical research attention during the pandemic has focused on college student perceptions of grading assessment (Guskey, 2020) which was one focus of this study. Grading assessment learning perceptions (GALP) assess a student's perception that the grading methods used in a course best measure their knowledge and skills (Blau, Gaffney, Kim, \& Jarrell, 2017; Blau, Goldberg, \& Szwczuk, 2020). In a typical college syllabus, there are often different grading assessment criteria, such as: journals, quizzes, tests, individual cases/papers, presentations, participation, attendance, as well as team/group projects (Flores, Veiga Simao, Barros, \& Pereira, 2015). An online course may also include discussion and message boards. Flores et al. (2015) found that grading assessment methods (e.g., individual and group portfolios) were regarded as fairer and more effective by undergraduates when they were more actively and creatively involved (e.g., individual and group portfolios) versus more conventionl methods (e.g., written tests). However, although Flores et al. (2015) did not develop grading assessment method scales, their results suggested that aggregating individual grading assessment techniques into broader scales could be done. Research by Blau and colleagues (Blau et al., 2017; Blau et al., 2020) found that four reliable, distinct GALP scales could be developed: exam-based - e.g., multiple choice exams/quizzes); individual creative - e.g., individual written assignments (case analyses, essays, etc.); individual engagement - e.g., class participation; and team-based - e.g., team written assignments. Blau, Williams, Jarrell \& Nash (2019) found each of these GALP scales to be positively related to college students' business degree satisfaction. One purpose of this study was to extend prior GALP research by examining graduating business student perceptions prior to and in the early stage of the pandemic, to see if there were changes in these four GALP scales. Also assessed prior to and in the early pandemic stage were student perceptions for using the Business school's video vault (De, Pandey, \& Pal, 2020), self-reported internships/co-ops as a student (Center for Research on College Workforce Transitions, 2021), and satisfaction with one's major and satisfaction with the business degree progam.

\subsection{Research Question}

The goals of this study were two-fold: (1) investigate changes from pre-pandemic to early pandemic in eight student-related perceptions: four GALP scales, video vault use, internships/co-ops completed, satisfaction with major and satisfaction with business degree; and (2) measure changes in the perceived relationships of six "independent variables," i.e., four GALP scales, video vault use, and internships/co-ops completed to two "dependent variables," i.e., satisfaction with major and satisfaction with business degree satisfaction. These variables are defined in the Measures section below.

\section{Method}

\subsection{Participants and Procedure}

Two separate groups of graduating undergraduate business students filled out an online survey in May, 2019 (pre-pandemic) and May, 2020 (early pandemic) semesters. The research site was a large United States (US) public-supported university business school, located in the Mid-Atlantic region. Via multiple emails and advisor reminders, all business seniors were asked, prior to graduating, to voluntarily fill out an online Senior Student Satisfaction Survey (SSSS). All study measures used here were part of the SSSS. These measures were identical for both surveys. Separate data bases for each survey were stored in Qualtrics. In May of 2019, 724 graduating seniors responded by completing the SSSS measures used in this study. This participation rate represented about $68 \%$ of the graduating seniors $(\mathrm{n}=1,070)$. In May 2020, 376 students completed these same SSSS measures, which represented approximately $31 \%$ of the graduating seniors $(n=1,200)$. The onset of the COVID-19 pandemic, half-way through the Spring 2020 semester (with seven weeks remaining), required the University to suddenly shift to all remote (no in-person) classes on March 13, 2020. This switch to remote learning necessitated the quick adoption by faculty teaching in-person classes to Zoom technology. The Business School Online \& Digital Learning Department provided immediate online training to facilitate the faculty use of Zoom. In addition, all on-campus students needed to move out of campus housing due to the pandemic. These factors, suddenly switching to all remote classes and forced evacuation of the campus, negatively impacted the May 2020 participating sample size. Ongoing SSSS collection of each graduating business student class had prior approval by the the university institutional review board (IRB). Ninety-six percent of each sample were full-time students (taking at least 12 credits/semester), and had slightly higher male participants (52\% in 2019; 51\% in 2020). Thus the sample sizes used for this study were, $n=724$ (2019) and $n=376$ (2020). 


\subsection{Measures}

Grading Assesment Learning Perception (GALP) items. The referent: "please indicate your level of agreement with the following statement: I find the following grading methods best reflect my course knowledge and skills," was used for 13 items. A 6-point response scale was used, where $1=$ strongly disagree to $6=$ strongly agree. Prior research (Blau et al., Jarrell, 2017; Blau et al., 2020) found that all except one of the 13-items loaded onto one of four GALP scales. The 13 items were collectively based on the graded components within the Business School's quantitative and qualitative (non-quantitative) Bachelor of Business Administration (BBA) core (required) lower and upper course syllabi. This prior work had identitifed four GALP scales (number of items): exam-based (3), e.g., multiple choice exams/quizzes; individual creative (3), e.g., individual written assignments (case analyses, essays, etc.); individual engagement (4), e.g., attendance and class participation; and team-based (2), e.g., team written assignments (case analyses, essays, etc.), and team presentations (oral/visual communication). Prior internal consistency estimates for these scales were: exam-based - .76 and .74; individual creative - .72 and .68; individual engagement - .77 and .74; and team-based - .82 and .81 (Blau et al., 2017); and exam-based - .79; individual creative - .67; individual engagement - .80; and team-based - .80 (Blau et al., 2020). For the samples in this study, the same scale reliabilities were: exam-based - .78 (2019) and .75 (2020); individual creative - .72 (2019) and .70 (2020); individual engagement - .76 (2019) and .77 (2020); and team-based - .82 (2019) and .83 (2020). Thus, these scale reliabilities remained adequate for continued use in this study.

Video Vault Use. This single item was measured by asking: "how often did you use the Business School video vault." Where $1=\mathrm{I}$ have not used the video vault, $2=1$ to 5 times, $3=6$ to 10 times, $4=10$ to 20 times, and $5=$ more than 20 times. The Business Schol video vault is a collection of all online lecture videos that have been produced by the Business School Online and Digital Learning Department and Business School faculty, with over 3,500 videos, spanning topics from Accounting to Tourism. Working with the Business School Online and Digital Learning Department, the author has made 15-20 minute online video vault lectures on different human resource management topics, such as: emotional intelligenc, hiring, motivation, performance appraisal, leadership, change, and communication for course use. Access to the vault is gained through a student's username and password. Students may be required to watch online video lectures for an online course, or may be encouraged to voluntarily use the video vault during their coursework by their professors, especially if they are in major or upper-level courses and need to review concepts from prior classes.

Internships/co-ops completed. This single item was measured by asking "how many formal internships or co-ops did you complete while a student at this University?" Response options were $0=$ none, $1=1,2=2,3=3,4=4$, and $5=5$ or more times.

Satisfaction with Major. This single item was measured by asking, "overall I am satisfied with my college major," where 1 = strongly disagree, 2 = disagree, $3=$ slightly disagree, $4=$ slightly agree, $5=$ agree, and $6=$ strongly agree.

Satisfaction with Business Degree. One item asked, "overall I am satisfied with the Business School Bachelors of Business Administration program," with responses from $1=$ strongly disagree to $6=$ strongly agree.

Open item. Students were asked at the end of each survey, "what was the best part of your undergraduate business school experience." They needed to type in their optional response.

\subsection{Data Analyses}

Means, standard deviations, and correlations were separately calculated for the 2019 and 2020 samples. Independent sample t-tests were then performed to test for mean changes in the eight above-noted perceptual measures from 2019 to 2020 . Aftet this, independent sample t-tests were performed to test for correlational change in the perceived relationships of six "independent variables," i.e., four GALP scales video vault use, and internships/co-ops completed to two "dependent variables," i.e., satisfaction with major and business degree satisfaction. SPSS-PC (2018) was used for all data analyses. A cutoff of $p<.10$ (two-tailed) was used for indicating statistical significance. Prior research (Hopkins, Marshall, Batterham \& Hanin, 2008, p.6) argued that p $=.10$, with a $90 \%$ confidence is "an appropriate default level of confidence." Although many positive comments were made in the open item analyses, e.g., specific courses, professors, and business school-related experiences, for this study the open item analyses only focused on 2020 student comments relevant to the pandemic's impact on them as they were graduating. 


\section{Results}

3.1 Preliminary Results - Separate Tables for 2019 and 2020 Variable Means, Standard Deviations and Correlations

Prior to testing the research questions, means, standard deviations, and correlations, were computed and the results are presented in Tables 1 (2019) and Table 2 (2020) below.

Table 1. Means, Standard Deviations, Correlations for 2019 Data

\begin{tabular}{|c|c|c|c|c|c|c|c|c|c|c|}
\hline Variable Name & M & SD & 1 & 2 & 3 & 4 & 5 & 6 & 7 & 8 \\
\hline 1. Exam-Based GALP ${ }^{\mathrm{a}}$ & 4.27 & 1.06 & $(---)$ & & & & & & & \\
\hline 2. Individual Creative GALP ${ }^{a}$ & 4.61 & .91 & $.19 * *$ & $(---)$ & & & & & & \\
\hline 3. Team GALP ${ }^{a}$ & 4.00 & 1.31 & $.27 * *$ & $.33 * *$ & $(----)$ & & & & & \\
\hline 4. Individual Engagement GALP ${ }^{\mathrm{a}}$ & 3.86 & 1.17 & $.34 * *$ & $.37 * *$ & $.46^{* *}$ & $(---)$ & & & & \\
\hline 5. Video Vault Use ${ }^{\mathrm{b}}$ & 3.43 & 1.24 & .05 & $.11 * *$ & -.03 & .06 & $(----)$ & & & \\
\hline 6. Internships/Co-ops Completed ${ }^{\mathrm{c}}$ & 1.42 & 1.15 & $-.12 * *$ & .01 & -.01 & -.04 & -.01 & $(----)$ & & \\
\hline 7. Satisfaction with Major ${ }^{\mathrm{a}}$ & 4.95 & 1.09 & $.19^{* *}$ & $.25 * *$ & $.17^{* *}$ & $.09 *$ & .03 & .02 & $(---)$ & \\
\hline 8. Satisfaction with Business Degree ${ }^{a}$ & 4.76 & 1.07 & $.27 * *$ & $.26^{* *}$ & $.25 * *$ & $.17 * *$ & .03 & .01 & $.69 * *$ & (----) \\
\hline
\end{tabular}

$\mathrm{N}=724 .{ }^{*} \mathrm{p}<.05 ; * * \mathrm{p}<.01$ (two-tailed).

${ }^{a}$ Exam-based GALP (Grading Assessment Learning Perception); Individual Creative GALP, Team GALP, Individual Engagement GALP, Satisfaction with Major, Satisfaction with Business Degree, $1=$ strongly disagree to $6=$ strongly agree.

${ }^{\mathrm{b}}$ Video Vault Use, $1=$ not used, $2=1$ to 5 times, $3=6$ to 10 times, $4=10-20$ times, $5=$ more than 20 times.

${ }^{\mathrm{c}}$ Internships or Coops Completed, $0=$ none, $1=1,2=2,3=3,4=4,5=5$ or more.

Table 1 GALP scale results show moderate (Individual Engagement) to higher ((Individual Creative) mean levels (6-point response scale), with adequate variance. Other mean levesl reflect moderate use of the video vault, a lower level of internships/co-ops completed, and higher satisfaction on both variables, major and business degree. The inter-correlations among the four GALP scales is generally consistent with prior research (Blau et al., 2017; Blau et al., 2020), allowing them to be used as separate variables in further analyses. Similarly the two satisfaction variables, major and business degree, exhibit sufficient distinctiveness to be used separately in further analyses (Stevens, 1996). A student's college major would focus on specific courses in that discipline offered by one department, e.g., accounting, finance, human resources, marketing, statistics, etc., while the business degree would encompass the major's courses, but also many other courses, i.e., lower and upper business core classes, across other departments in the business school curriculum, as well as required non-business courses (e.g., General Education courses). Prior research on business student satisfaction supports this major versus business degree item distinction (Maddox \& Nicholson, 2008). 
Table 2. Means, Standard Deviations, Correlations for 2020 Data

\begin{tabular}{|c|c|c|c|c|c|c|c|c|c|c|}
\hline Variable Name & M & SD & 1 & 2 & 3 & 4 & 5 & 6 & 7 & 8 \\
\hline 1. Exam-Based GALP ${ }^{\mathrm{a}}$ & 4.29 & 1.06 & $(---)$ & & & & & & & \\
\hline 2. Individual Creative GALP ${ }^{a}$ & 4.56 & .91 & $.22 * *$ & $(----)$ & & & & & & \\
\hline 3. Team GALP ${ }^{\mathrm{a}}$ & 3.91 & 1.34 & $.21^{* *}$ & $.37 * *$ & $(---)$ & & & & & \\
\hline 4. Individual Engagement GALP ${ }^{\mathrm{a}}$ & 3.71 & 1.18 & $.32 * *$ & $.34 * *$ & $.44 * *$ & $(----)$ & & & & \\
\hline 5. Video Vault Use ${ }^{\mathrm{b}}$ & 3.68 & 1.28 & .03 & .06 & -.04 & .10 & $(----)$ & & & \\
\hline 6. Internships/Co-ops Completed ${ }^{\mathrm{c}}$ & 1.55 & 1.24 & $-.12 * *$ & .05 & $-.13 * *$ & -.08 & .03 & $(---)$ & & \\
\hline 7. Satisfaction with Major ${ }^{\mathrm{a}}$ & 4.95 & 1.16 & $.25 * *$ & $.28 * *$ & $.18^{* *}$ & $.17 *$ & $.13^{*}$ & -.04 & $(----)$ & \\
\hline 8. Satisfaction with Business Degree ${ }^{a}$ & 4.74 & 1.15 & $.31 * *$ & $.39 * *$ & $.28 * *$ & $.30 * *$ & .09 & -.09 & $.67 * *$ & $(----)$ \\
\hline
\end{tabular}

$\mathrm{N}=376 .{ }^{*} \mathrm{p}<.05 ; * * \mathrm{p}<.01$ (two-tailed)

${ }^{a}$ Exam-based GALP (Grading Assessment Learning Perception); Individual Creative GALP, Team GALP, Individual

Engagement GALP, Satisfaction with Major, Satisfaction with Business Degree, $1=$ strongly disagree to $6=$ strongly agree.

${ }^{\mathrm{b}}$ Video Vault Use, $1=$ not used, $2=1$ to 5 times, $3=6$ to 10 times, $4=10-20$ times, $5=$ more than 20 times

${ }^{\mathrm{c}}$ Internships or Coops Completed, $0=$ none, $1=1,2=2,3=3,4=4,5=5$ or more

The results in Table 2 are consistent with Table 1, and include allowing the four GALP scales and two satisfaction items to be used separarely in further analyses. Finding each of the four GALP scales to be positively related to the two separate satisfaction varibles in both Tables is consistent with prior work (Blau et al. 2019).

\subsection{Tests of Research Questions}

Independent sample t-tests were computed between the 2019 versus 2020 variables to test the first research question, i.e., if there were any significant changes. Exact $p$ values to hundredths are reported (Stevens, 1996). The results are shown in Table 3 below.

Table 3. Independent Sample t-tests between 2019 and 2020 Means

\begin{tabular}{|c|c|c|c|c|c|c|}
\hline \multirow{2}{*}{ Variable Name } & \multicolumn{2}{|c|}{$2019(n=724)$} & \multicolumn{2}{|c|}{$2020(n=376)$} & \multirow{2}{*}{ T-test Value } & \multirow{2}{*}{ P value } \\
\hline & $\mathbf{M}$ & SD & $\mathbf{M}$ & SD & & \\
\hline 1. Exam-based GALP ${ }^{\mathrm{a}}$ & 4.27 & 1.06 & 4.29 & 1.06 & -.14 & $\mathrm{p}=.88$ \\
\hline 2. Individual Creative GALP ${ }^{a}$ & 4.61 & .91 & 4.56 & .92 & 1.03 & $\mathrm{p}=.30$ \\
\hline 3. Team GALP ${ }^{\mathrm{a}}$ & 4.00 & 1.31 & 3.91 & 1.34 & 1.07 & $\mathrm{p}=.28$ \\
\hline 4. Individual Engagement GALP & 3.86 & 1.17 & 3.71 & 1.19 & 2.01 & $p=.04$ \\
\hline 5. Video Vault Use ${ }^{b}$ & 3.43 & 1.24 & 3.68 & 1.28 & -3.21 & $p=.01$ \\
\hline 6. Internships/co-ops completed & 1.42 & 1.15 & 1.55 & 1.24 & -1.69 & $p=.09$ \\
\hline 7. Satisfaction with Major ${ }^{\mathrm{c}}$ & 4.95 & 1.09 & 4.95 & 1.16 & -.13 & $\mathrm{p}=.89$ \\
\hline 8. Satisfaction with Business Degree Program ${ }^{c}$ & 4.76 & 1.07 & 4.74 & 1.15 & .72 & $\mathrm{p}=.48$ \\
\hline
\end{tabular}

( $p$ tests are two-tailed).

${ }^{\mathrm{a}} \mathrm{GALP}=$ Grading Assessment Learning Perception, $1=$ strongly disagree to $6=$ strongly agree $;{ }^{\mathrm{b}}$ Video Vault Use, $1=$ not used, $2=1$ to 5 times, $3=6$ to 10 times, $4=10-20$ times, $5=$ more than 20 times; Satisfaction with Major, Satisfaction with Business Degree Program, $1=$ strongly disagree to $6=$ strongly agree.

The results in Table 3 showed three significant mean level changes from 2019 to 2020 (bolded). Student perceptions of Individual Engagement GALP decresed from $2019(M=3.86)$ to $2020(M=3.71), t(1,098)=2.01$, $p=.04$; there were increased perceptions for video vault use, from $2019(M=3.43)$ to $2020(M=3.68), t(1,098)=$ $-3.21, p=.01$; and finally student perceptions increased for internships/co-ops completed, from $2019(M=1.42)$ to $2020(M=1.5), t(1,098)=-1.69, p=.09$. For all other variables, there were no significant mean changes from 2019 
to 2020 .

To test the second research question, independent sample t-tests were performed for changes in the perceived relationships of the four GALP scales, i.e., exam-based, individual creative, team, and individual engagement, as well as video vault use and internships/co-ops completed, used as "independent variables," to satisfaction with major and satisfaction with business degree program, used as "dependent variables." Exact $p$ values to hundredths are reported (Stevens, 1996). These results are shown in Table 4.

Table 4. T-tests for Correlation Changes from 2019 to 2020 on Satisfaction with Major and Business Degree Satisfaction

\begin{tabular}{|c|c|c|c|c|c|c|}
\hline \multirow[b]{2}{*}{ Variable Name } & 2019 & 2020 & \multirow[b]{2}{*}{ t-test $\&$ p value } & 2019 & 2020 & \multirow[b]{2}{*}{$\begin{array}{l}\text { t-test } \\
\text { value }\end{array}$} \\
\hline & $\begin{array}{l}\text { Major Sat }^{\mathrm{c}} \\
\text { correlation }\end{array}$ & $\begin{array}{l}\text { Major Sat } \\
\text { correlation }\end{array}$ & & $\begin{array}{l}\text { Degree Sat }^{d} \\
\text { correlation }\end{array}$ & $\begin{array}{l}\text { Degree Sat }^{\mathrm{d}} \\
\text { correlation }\end{array}$ & \\
\hline \multicolumn{7}{|l|}{ Correlate } \\
\hline 1. Exam-based GALP ${ }^{\mathrm{a}}$ & .19 & .25 & $\mathrm{t}=-.99, \mathrm{p}=.16$ & .27 & .31 & $\mathrm{t}=-.69, \mathrm{p}=.25$ \\
\hline 2. Individual Creative GALP ${ }^{\mathrm{b}}$ & .25 & .28 & $\mathrm{t}=-.51, \mathrm{p}=.36$ & .26 & .39 & $\mathrm{t}=-2.28, \mathrm{p}=.01$ \\
\hline 3. Team GALP Individual & .17 & .18 & $\mathrm{t}=-.16, \mathrm{p}=.44$ & .25 & .28 & $\mathrm{t}=-.51, \mathrm{p}=.31$ \\
\hline 4. Engagement GALP & .09 & .17 & $\mathrm{t}=-1.28, \mathrm{p}=.10$ & .17 & .30 & $t=-2.16, p=.02$ \\
\hline 5. Video Vault Use ${ }^{\mathrm{b}}$ & .03 & .13 & $\mathrm{t}=-1.58, \mathrm{p}=.06^{+}$ & .03 & .09 & $\mathrm{t}=-.94, \mathrm{p}=.17$ \\
\hline 6. Internships/Co-ops Completed & .02 & -.04 & $\mathrm{t}=.94, \mathrm{p}=.17$ & .01 & -.09 & $\mathrm{t}=-1.57, \mathrm{p}=.06^{+}$ \\
\hline
\end{tabular}

$2019 \mathrm{n}=724 ; 2020 \mathrm{n}=376^{*} p<.05 ;+p<.10$

${ }^{a}$ Exam-based GALP (Grading Assessment Learning Perception); Individual Creative GALP, Team GALP, Individual Engagement GALP; ${ }^{\mathrm{b}}$ Video Vault Use; ${ }^{\mathrm{c}}$ Satisfaction with Major; ${ }^{\mathrm{d}}$ Satisfaction with Business Degree

Four significant results are shown in Table 4, and three are changes in the correlations from 2019 to 2020 in Satisfaction with Business Degree (bolded). Individual Creative GALP has a stronger relationship to 2020 Business Degree Satisfaction $(r=.39)$ than to 2019 Business Degree Satisfaction $(r=.26)$, i.e., $t(1,098)=-2.28, p$ $=.01$. In addition, Individual Engagement GALP has a stronger relationship to 2020 Business Degree Satisfaction $(r=.30)$ than to 2019 Business Degree Satisfaction $(r=.17)$, i.e., $t(1,098)=-2.16, p=.02$. Finally, Internships/Co-ops completed has a stronger relationship to 2020 Satisfaction with Business Degree $(r=-.09)$ than to 2019 Satisfaction with Business Degree $(r=.01)$, i.e., $t(1,098)=-1.57, p=.06$. There is one significant change in the correlatons from 2019 to 2020 for Satisfaction with major. Video vault use has a stronger relationship to 2020 Satisfaction with Major $(r=.13)$ than to 2019 Satisfaction with Major $(r=.03)$, i.e., $t(1,098)=-1.58, p=.06$.

\section{Dicussion}

Although acknowledged to be important, less empirical research attention during the pandemic has focused on college student perceptions of grading assessment (Guskey, 2020). This study extends prior GALP research (Blau et al., 2017; Blau et al., 2019, Blau et al., 2020) by examining graduating business student perceptions prior to and in the early stage of the pandemic, to see if there were changes in the GALP scales. Only one GALP scale changed from 2019 to 2020, Individual Engagement, and it significantly declined. This scale measures items including class attendance and participation. This decrease seems understandable due to the pandemic's impact. Students were suddenly forced to leave the main campus and all face-to-face classes were cancelled on March 13, 2020, and abruptly converted to online Zoom classes approximately half-way through the Spring 2020 semester. At the same time, with the conversion to all-remote classes, student video vault use significantly increased to help students keep up with their new remote classes (De et al., 2020). Credit goes to the Business School Online and Digital Learning Department for working with the faculty to prepare such videos prior to the pandemic onset. Students also reported an increase in internships/co-ops completed. Perhaps more importantly, the results in Table 3 show no signficiant change in all other variable means from 2019 to 2020, suggesting that despite the sudden onset of the pandemic, Business School professors maintained enough course work stability during the second half of the Spring 2020 semester so that exam-based, individual creative and team GALP scales were not significantly affected. It should be noted that the maintained constancy for these three GALP scale means was at least partially due to the quick training and resources given by the Business School Online and Digital Learning Department to 
those faculty who had to abruptly transition from face-to-face to online course teaching via Zoom. This is consistent with prior research showing the sudden shift in teaching to online learning with the pandemic onset (Rapanta et al., 2020). In addition, satisfaction with major and satisfaction with the business degree program also remained consistently high from 2019 to 2020 . Overall these results indicate that the Business School did well at generally keeping student perceptions stable (compared to 2019) in the early stage of the pandemic. This is perhaps even more commendable given that students had gone through a normal 14-week Spring 2019 semester, a normal 14-week Fall 2019 semester, and seven weeks of a normal Spring 2020 semester before suddenly being forced to change.

Looking at changes in variable correlations from 2019 to 2020, there was an increase in the correlation of video vault use to satisfaction with major. This reinforces speculation that the availability of videos helped students feel that they could keep up in their major courses (De et al., 2020). The increases in the individual creative GALP satisfaction with business degree and individual engagement GALP - satisfaction with business degree correlations may be partially due to business professors being encouraged to be flexible, by upper-level administration, in accommodating students as they finished up the semester under much more difficult than normal circumstances. For example, the author switched his final exam in the Spring 2020 semester from a traditional in-class multiple choice final exam to an online case study, allowing for more student creativity in answering/applying course material. As noted earlier, research has found that students appreciate grading assessments where they can be more actively and creatively involved (Flores et al., 2015). One unexpected finding was the increased negative correlation of internships/co-ops completed to business degree satisfaction from 2019 to 2020, despite the higher mean level of internships/co-ops completed in 2020. It is here that the 2020 open item students' comments from the SSSS provided some insights for this finding, including some businesses postponing or even canceling students' transitions from an internship to full-time employment after their graduation because of the pandemic.

\subsection{Study Limitations}

The dramatic decrease in complete sample size (participation percentage) from 2019, $\mathrm{n}=724(68 \%)$ to 2020, $\mathrm{n}=$ $376(31 \%)$, when the pandemic first began, was understandable but still troubling. This decrease, and an ongoing concern about a continued/increased graduating student voluntary participation rate drop off led to an administrative decision to cancel the Spring 2021 SSSS. However, this decision prevented additional data collection for comparision in a later stage of the pandemic. Therefore, this research only reported early pandemic student perceptions on the variables studied. The next Spring SSSS is planned to resume in 2022 under hopefully more favorable voluntary student participation conditions. There are other study limitations to note. Since the SSSS is a retrospective graduation-based survey, students needed to accurately remember and aggregate their perceptions over time, e.g., GALP scales, video vault use, internships/co-ops completed. Video vault use was measured using only one item that collapsed response use frequencies together into categories. Asking students for an absolute frequency of use may have led to stronger results. Unfortunately, there was no direct measure asking students about their perceptions of the video vault, beyond use. All data were collected at one time point, so although satisfaction with major and satisfaction with business degree were classified as "dependent variables" when testing for changes in correlations, causality can not be inferred. One item measures of satisfaction with major and business degree did not allow for calculating reliability estimates. Despite the more limited 2020 sample size issue, bigger absolute sample sizes allow more power for detecting significant mean level differences (Stevens, 1996), which may not be as large in absolute terms. Method bias is a concern because only self-reported measures were used. When entering all of the items into a principal compents analysis (PCA), the one-factor test for the 2019 sample found six factors, each with an eigenvalue of over 1. Twenty-six percent of the total variance was accounted for by the first factor in the 2019 sample. For the 2020 sample, the one-factor test also found six factors with the first factor accounting for $27 \%$ of the total variance. If these first factors each represent self-report method bias (Podsakoff, MacKenzie, Lee, \& Podsakoff, 2003), they are not an overriding study limitation. Spector (2006) argued that self-report method bias does not inflate study results to a significant degree. Of course, future research efforts should try to also collect additional non-self-report (e.g., record-based frequency of video use) or other source data (e.g., documented internships/co-ops). There was no direct measure of faculty perceptions for Zoom training by the Business School Online and Digital Learning Department. Both student samples were similar on gender and full-time status percentages. However, other sample demographic comparisons could not be made due to a lack of data (e.g., ethnicity, age, specific business major).

\subsection{Future Research}

Clearly, other types of college student samples need to be studied in future research, e.g., non-United States (US) students, non-business students, and part-time student status, to test the generalizability of these initial findings 
(Del Gaizo Moore, et al., 2021). When focusing on only business students, if sample sizes permit, separating out different specific majors, e.g., accounting, finance, marketing, and management, for comparison could be useful. Gathering data on how prepared students believed they were for their careers upon graduation, especially given the ongoing pandemic, will be important for future research to study. Also, has the pandemic caused students to change majors or their career plans while in college? This could include items measuring transferring to another college within a University or changing Universities, or even putting their education on hold.

\subsection{Conclusion}

The continuing pandemic will force colleges and universities around the world grapple with student academic learning issues. With the uncertainty abut how "normal" college life will be for all stakeholders in Fall 2021 (McCormack et al., 2021), continued study of these teaching-related issues, including student perceptions, remains important. Given the global experience of universities stuggling with the ongoing pandemic's impact (Tam et al., 2021; Watermeyer, Crick, Knight, \& Goodall, 2021), an international collaborative effort among researchers comparing the same student perception variables across different college settings, e.g., United States versus other countries, state-supported versus private, urban versus rural campus location, business versus non-business school, and full-time versus part-time undergraduates, would be ideal for future research. This collaborative effort could also hopefully address the above-noted study limitation by encompassing not only early pandemic but later pandemic stage(s) data collection.

\section{References}

Balakrishnan, P. (2020). Education responses in the age of COVID-19: Educational responsese from four Southeast Asian Countries. International Studies in Educational Administration (CCEA), 48(3), 102-108. Retrieved from https://www.researchgate.net/profile/Scott-Eacott/publication/344440266_COVID-19_and Inequities_in_Australian_Education_-_Insights_on_Federalism_Autonomy_and_Access/links $/ 5 \mathrm{f} 75 \mathrm{~b} 508928$ 51c14bca43c28/COVID-19-and-Inequities-in-Australian-Education-Insights-on-Federalism-Autonomy-and -Access.pdf

Blau, G., Gaffney, M. A., Kim, Y. J., \& Jarrell, S. (2017). Do grading assessment learning perceptions correlated to post-graduate outcomes? Journal of Assessment and Institutional Effectiveness, 7(1-2), 69-91. https://doi.org/10.5325/jasseinsteffe.7.1-2.0069

Blau, G., Goldberg, D., \& Szewczuk, R. (2020). Exploring the relationships of grading learning assessment perceptions to perceived added education value required course business scales. Journal of Education and Development, 4(2), 58-67. https://doi.org/10.20849/jed.v4i2.775

Blau, G., Williams, W., Jarrell, S., \& Nash, D. (2019). Exploring common correlates of business undergraduate satisfaction with their degree program versus expected employment. Journal of Education for Business, 94(1), 31-39. https://doi.org/10.1080/08832323.2018.1502144

Center for Research on College Workforce Transitions. (2021). New study reveals that only 22 percent of college students did internships during the pandemic. School of Education. University of Wisconsin-Madison. Retrieved June, 16, 2021, from https://education.wisc.edu/news/new-study-reveals-only-22-percent-ofcollege-students-did-internships-during-pandemic/

Chinawa, A. T., Chinawa, J. M., Ossar, E. N., \& Onukwuli, V. O. (2021). The COVID 19 Pandemic: College adolescents' perception on school reopening in Nigeria. Journal of Educational and Developmental Psychology, 11(2), 29-38. doi:10.5539/jedp.v11n2p29

De, R., Pandey, N., \& Pal, A. (2020). Impact of digital surge during the COVID-19 pandemic: A viewpoint on research and practice. International Journal of Information Management, 55, 1-5. https://doi.org/10.1016/j.ijinfomgt.2020.102171

Del Gaizo Moore, V., Scheifele, L, Chihade, J., Provost, J., Roeckein-Canfield, J., Tsotakos, N., \& Wolyniak, M. (2021). COVID-360: A collaborative effort to develop a multidisciplinary set of online resources for engaging teaching on the COVID-19 pandemic. Journal of Microbiolgy and Biology Education, 22(1), 1-8. https://doi.org/10.1128/jmbe.v22i1.2623

Flores, M., Veiga Simao, A., Barros, A., \& Pereira, D. (2015). Perceptions of effectiveness, fairness, and feedback of assessment methods: A study in higher education. Studies in Higher Education, 40(9), 1523-1534. https://doi.org/10.1080/03075079.2014.881348

Friga, B. N. (2021). How much asd COVID cost colleges? \$183 billion. The Chronicle of Higher Education. February 5, 2021. https://www.chronicle.com/article/how-to-fight-COVIDs-financial-crush 
Guskey, T. (2020). Assessments and grading in the midst of a pandemic. Education Week. April, 13, 2020. Retrieved from https://www.edweek.org/education/opinion-assessments-and-grading-in-the-midst-of-apandemic/2020/04

Hasratian, A. M., Nordberg, H. O., Meurt, A. E., \& Ritz, T. (2021). Fear and coping in students during the earlystages of the COVID-19 Pandemic: A combined cross-sectional and longitudinal study. International Journal of Environmental Research and Public Health, 18, 6551. https://doi.org/10.3390/ijerph18126551

Hopkins, W. G., Marshall, S. W., Batterham, A. M., \& Hanin, J. (2008). Progressive statistics for studies in sports medicine and exercise science. Medicine \& Science in Sports \& Exercise, 40, 1-10. https://doi.org/10.1249/MSS.0b013e31818cb278

Konstantoupolou, G., \& Raikou, N. (2020). Clinical evaluation of depression on university students during quarantine due to COVID-19 pandemic. European Journal of Public Health Studies, 3(1), 1-7. https://doi.org/10.46827/ejphs.v3i1.65

Maddox, E. N., \& Nicholosn, C. Y. (2008). The Business Student Satisfaction Inventory (BSSI): Development and validation of a global measure of student satisfaction. Developments in Business Simulation and Experiential Learning, 35, 101-112. Retrieved from https://journals.tdl.org/absel/index.php/absel/article/view/393

McCormack, T., J., Lemoine, P. A., Waller, R. E., \& Richardson, M. D. (2021). Global higher education: Examining response to the COVID-19 pandemic using agility and adaptability. Journal of Education and Development, 5(1), 10-16. https://doi.org/10.20849/jed.v5i1.848

Neuwirth, L. S., Jović, S., \& Mukherji, B. R. (2020). Reimagining higher education during and post-COVID-19: Challenges and opportunities. Journal of Adult and Continuing Education. https://doi.org/10.1177/1477971420947738

Plater, R. (2021). Delta Plus, Epsilon, Gamma: New COVID-19 variants have scientists worried. Healthline. Retrieved June 29, 2021, from https://www.healthline.com/health-news/delta-plus-epsilongamma-new-COVID-19-variants-have-scientists-worried\#Other-worrisome-variants

Podsakoff, P., Mackenzie, S., Lee, J., \& Podsakoff, N. (2003). Common method biases in behavioral research: Critical review of the literature and recommended remedies. Journal of Applied Psychology, 88(5), 879-903. https://doi.org/10.1037/0021-9010.88.5.879

Rapanta, C., Botturi, L., Goodyear, P., Guardia, L., \& Koole, M. (2020). Online university teaching during and after the COVID-19 Crisis: Refocusing teacher presence and learning activity. Postdigital Science and Education, 2, 923-945. https://doi.org/10.1007/s42438-020-00155-y

Sainato, M. (2021). US universities hit by protests over cuts, tuition, right to unionize. The Guardian. Retrieved February 24, 2021, from https://www.theguardian.com/education/2021/feb/24/us-universities-protests-cuts-tuition-right-to-unionize

Spector, P. (2006). Method variance in organizational research: Truth or urban legend? Organizational Research Methods, 9(2), 221-232. https://doi.org/10.1177/1094428105284955

Stevens, J. (1996). Applied multivariate statistics for the social sciences (2nd ed.). Mahwah, NJ: Lawrence Erlbaum.

SPSS-PC, version 25. (2018). Statistical package for the social sciences. Chicago: IBM Corporation.

Tam, C. C., Li, X., Li, X., Wang, Y., \& Lin, D. (2021). Adherence to preventive behaviors among college students during COVID-19 pandemic in China: The role of health beliefs and COVID-19 stressors. Current Psychology. https://doi.org/10.1007/s12144-021-01942-x

Watermeyer, R., Crick, T., Knight, C., \& Goodall, J. (2021). COVID-19 and digital disruption in UK universities: Afflictions and affordances of emergeny online migration. Higher Education, 81, 623-641. https://doi.org/10.1007/s10734-020-00561-y

\section{Copyrights}

Copyright for this article is retained by the author(s), with first publication rights granted to the journal.

This is an open-access article distributed under the terms and conditions of the Creative Commons Attribution license (http://creativecommons.org/licenses/by/4.0/). 